\title{
Circulating Tumor Cells and PET
}

\author{
Jian Q. Yu ${ }^{1}$ and Massimo Cristofanilli ${ }^{2}$ \\ ${ }^{1}$ Department of Radiology, Fox Chase Cancer Center, Philadelphia, Pennsylvania; and ${ }^{2}$ Department of Medical Oncology, Fox Chase \\ Cancer Center, Philadelphia, Pennsylvania
}

\begin{abstract}
Understanding the distinct molecular features of solid tumors provides the opportunity to develop more targeted and effective therapies. The evaluation and monitoring of these therapies require sophisticated laboratory and imaging technologies to detect potential benefit not necessarily translating into significant changes in tumor size. PET has emerged as the most sensitive imaging technique for providing the metabolic profile of an individual tumor. Most recently, the detection of circulating tumor cells in the peripheral blood of patients with advanced malignancies has provided another dimension to the use of PET for sensitive therapeutic monitoring. Moreover, molecular characterization of circulating tumor cells holds promise for furthering the care of cancer patients.
\end{abstract}

Key Words: blood biomarkers; circulating tumor cells; PET imaging

J Nucl Med 2011; 52:1501-1504

DOI: 10.2967/jnumed.111.097683

PET is an imaging technique that provides a 3-dimensional picture of functional processes in the body. Stateof-the-art PET/CT hybrid imaging combines information on the physiologic or pathologic distribution of a PET tracer with anatomic information. Molecular imaging, as defined by the Society for Nuclear Medicine (1), is the visualization, characterization, and measurement of biologic processes at the molecular and cellular levels in humans and other living systems.

\section{PET IN ADVANCED CANCER: EMERGING ROLE AND FUTURE DIRECTIONS}

Scientists and clinicians have been looking for tracers that allow for better diagnosis and monitoring of disease. There are many tracers labeled with ${ }^{11} \mathrm{C}\left(20\right.$-min half-life), ${ }^{13} \mathrm{~N}$ (10-min half-life), and ${ }^{15} \mathrm{O}$ (2-min half-life), but their extremely short half-lives require an onsite cyclotron. These tracers are therefore usually available only in research and major academic institutions. Because of the longer half-life

Received Aug. 30, 2011; accepted Aug. 30, 2011.

For correspondence or reprints contact: Massimo Cristofanilli, 333

Cottman Ave., Philadelphia, PA 19111.

E-mail: massimo.cristofanilli@fccc.edu

Published online Sep. 12, 2011.

COPYRIGHT (c) 2011 by the Society of Nuclear Medicine, Inc. of ${ }^{18} \mathrm{~F}$ ( $\left.\sim 2 \mathrm{~h}\right),{ }^{18} \mathrm{~F}$-labeled compounds generally can be shipped and have the potential for widespread clinical use.

Currently, only 1 PET tracer is approved for routine use in the clinic: ${ }^{18} \mathrm{~F}$-FDG. ${ }^{18} \mathrm{~F}$-FDG PET is used in oncology; cardiology, and neurology, with oncologic applications being the most common. ${ }^{18} \mathrm{~F}-\mathrm{FDG}$ PET is based on the principle that diseased or tumor cells use more glucose for metabolism and produce higher signals than normal tissues and the background. One major strength of ${ }^{18} \mathrm{~F}-$ FDG PET is the ability to detect metastatic disease (Fig. 1). However, inflammation and infection can also take up ${ }^{18} \mathrm{~F}$ FDG and are major confounding factors on ${ }^{18} \mathrm{~F}-\mathrm{FDG}$ PET images. In addition, the utility of ${ }^{18} \mathrm{~F}-\mathrm{FDG}$ for monitoring early response to therapy is somewhat limited.

Advances in technology make personalized medicine possible. Tracer targets and disease control have many aspects. The ideal tracer will be the right probe for the right target, for the right process, at the right time. If we have that perfect tracer, we should be able to provide patients with optimal care. One recent article about cancer drugs in the New England Journal of Medicine (2) discussed drug costs and methods of controlling disease. One meaningful method of control might be proper monitoring of the disease process and optimal use of cancer drugs.

Common targets include metabolism, inflammation and infection, proliferation, hypoxia, angiogenesis, and apoptosis. The first 2 targets have been extensively studied by ${ }^{18} \mathrm{~F}$-FDG PET and are well incorporated into the daily practice of oncology. The next available tracer will most likely be $3^{\prime}$-deoxy- $3^{\prime}-{ }^{18} \mathrm{~F}$-fluorothymidine $\left({ }^{18} \mathrm{~F}\right.$-FLT), which will be used to monitor proliferation (3). ${ }^{18} \mathrm{~F}$-FLT is the current tracer for proliferation, and many articles focus on its use as a way to detect changes early after therapy and as an early predictor of prognosis (4-6). Our experiences at Fox Chase Cancer Center with multicenter trials and several in-house clinical studies concur with the findings in the literature.

Hypoxia is another process commonly studied with novel PET tracers and imaging. A search of clinicaltrials.gov revealed over 30 trials involving hypoxia PET tracers. These include ${ }^{18} \mathrm{~F}$-FMISO (fluoromisonidazole), ${ }^{18} \mathrm{~F}$-FAZA (azomycin arabinoside), ${ }^{18} \mathrm{~F}-\mathrm{EF} 3$ (2-(2-nitroimidazol-1-yl)$N$-(3,3,3-trifluoropropyl)-acetamide) and ${ }^{18} \mathrm{~F}$-EF5 (2-(2-nitro$1 H$-imidazol-1-yl)- $N$-(2,2,3,3,3- pentafluoropropyl)-acetamide), copper-labeled ATSM (diacetyl-bis $\left(N^{4}\right.$-methythiosemicarba- 
FIGURE 1. Three-dimensional PET/CT (coronal, sagittal, and transaxial), performed for restaging in 56-y-old woman with breast cancer, shows multiple active lesions consistent with metastasis. Bone involvement is extensive (blue arrow), and right lung lesion with mediastinal involvement is seen (green arrow). PET/CT clearly demonstrates full extent of disease.

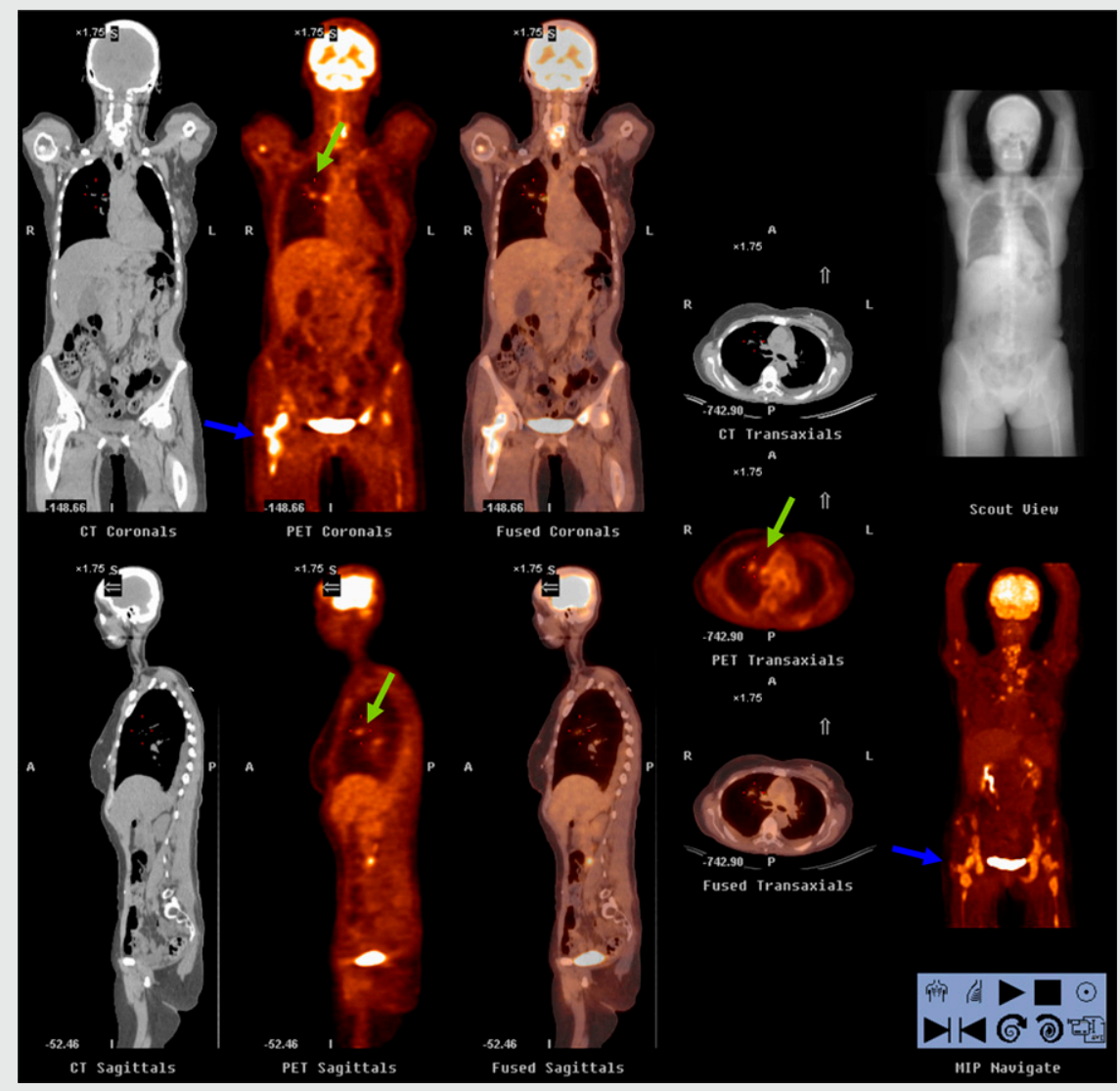

zone)), ${ }^{124} \mathrm{I}$-IAZGP (iodoazomycin galactopyranoside), ${ }^{18} \mathrm{~F}-$ HX4 (3-fluoro-2-(4-((2-nitro-1 $H$-imidazol-1-yl)methyl)- $1 H$ 1,2,3-triazol-1-yl)propan-1-ol), and ${ }^{18} \mathrm{~F}-\mathrm{VM} 4 .{ }^{18} \mathrm{~F}-\mathrm{FMISO}$ appears to be the most commonly used tracer for hypoxia and has been extensively studied (7-9), followed by copper-labeled ATSM. Our institution has been involved with studies of both ${ }^{18} \mathrm{~F}-\mathrm{HX} 4$ and ${ }^{18} \mathrm{~F}-\mathrm{VM} 4$. The former has completed phases 0 (10) and 1 (11) and is currently in a phase 2 multicenter clinical trial in the United States. The American College of Radiology Imaging Network (ACRIN) is a National Cancer Institute cooperative group and currently sponsors 2 hypoxia PET trials: ${ }^{18} \mathrm{~F}-\mathrm{FMISO}$ for glioblastoma (ACRIN 6684) and ${ }^{64} \mathrm{Cu}$-ATSM for cervical cancer (ACRIN 6682). The trials should be completed and results available in the next few years.

Angiogenesis is the growth of new blood vessels. Many tumors have a higher ability to undergo angiogenesis, and there are several drugs that target this property as a means to combat cancer. The most commonly studied angiogenesis PET tracer is RGD, which is the Arg-Gly-Asp peptide. This compound has been labeled as ${ }^{18} \mathrm{~F}$-galactoRGD, ${ }^{64} \mathrm{Cu}$-DOTA-RGD, and ${ }^{68} \mathrm{Ga}$-DOTA-RGD. There is commercial interest in this compound by several major vendors with ongoing clinical trials.

The ability to undergo apoptosis, or programmed cell death, is lost by many cancer cells. There are several signal transduction pathways. The main compounds being researched are annexin- $\mathrm{V}$ and its derivatives, labeled with ${ }^{18} \mathrm{~F}$ and ${ }^{64} \mathrm{Cu}$ for PET $(12,13)$. Because caspases are responsible for the cell death program and are potentially suitable targets for the imaging of apoptosis in vivo, they are the current research focus of several academic and commercial sites.

In summary, PET is an important aspect of molecular imaging. Various PET tracers can be used for diagnosis and for monitoring treatment response. Several tracers that have been in research for many years, such as ${ }^{18} \mathrm{~F}$-FLT and ${ }^{18} \mathrm{~F}$ FMISO, are near maturity. PET tracers focusing on disease processes rather than an individual tumor will have a wide spectrum. There are potential new tracers focusing on hypoxia, angiogenesis, and apoptosis. If we can find the proper tracer for every disease process, we can definitely improve patient care.

\section{CIRCULATING TUMOR CELLS: A NOVEL BIOMARKER IN ADVANCED BREAST CANCER}

Breast cancer is one of the most common malignancies in women, with an estimated 207,090 new cases diagnosed in the United States in 2010 (14). Despite advances in prevention, detection, and adjuvant therapy, a substantial number of patients are diagnosed at initial presentation or develop metastases further in the course of their disease. Standard prognostic and predictive factors that have proven useful for treatment selection include hormone receptor status for selection of endocrine therapy and human epider- 
mal growth factor receptor 2 (HER2) amplification or overexpression for selection of trastuzumab, but unfortunately, these factors provide limited information on the mechanisms of metastases and are not appropriate for prospective therapeutic monitoring (15).

Cancer dissemination via circulating tumor cells (CTCs) is a crucial part of the metastatic cascade. The detection of CTCs using the Food and Drug Administration-approved CellSearch technology (Veridex, LLC) has demonstrated prognostic value in patients with various forms of solid tumors, including breast, prostate, and colon cancer (16-18). Furthermore, the possibility of collecting sequential blood samples for real-time monitoring of the efficacy of systemic therapies opened a new avenue for the development of novel surrogate biomarkers that might improve the clinical management of patients with advanced disease and support research to clarify the peculiar biology of those cells (19). Some recent phenotypic assessments have suggested that a fraction of CTCs has properties of cancer stem cells $(20,21)$. Those data indicate the possibility of evaluating the effect of cancer stem cell-targeted therapies via profiling of CTCs to improve the efficacy of current treatments for metastatic disease.

In a series of studies, the baseline prognostic value of CTCs proved particularly useful in patients with newly diagnosed metastatic breast cancer (MBC) before they began first-line salvage therapy (22). In a single institution, a retrospective study of 185 patients diagnosed between 2001 and 2007 with 5 or more CTCs at baseline had a more than 3.5-fold higher risk of death (hazard ratio, 3.64; $95 \%$ confidence interval, 2.11-6.30; $P<0.0001)$ than patients with fewer than 5 CTCs. The prognostic significance of CTCs precluded choice of therapy (i.e., chemotherapy with anthracyclines, taxanes, or both; hormone therapy) and was also independent of hormone receptor status and HER2/neu status. Interestingly, in this cohort, although the patient demographics were representative of the phenotypic characteristics of MBC patients in general (i.e., approximately two thirds of patients hormone receptor-positive and approximately $20 \%$ HER2/neu-positive), more than half the patients had bone as their first site of metastatic disease. On multivariate analysis, patients with bone metastasis, compared with other sites of disease with 5 or more CTCs, had an additional risk of death (hazard ratio, 1.61; 95\% confidence interval, $0.52-5.04 ; P=0.410$ ). These interesting findings suggest that CTC enumeration can be used to monitor treatment along with standard imaging modalities.

In this regard, Budd et al. compared CTC monitoring with bidimensional response assessment (central review) in 177 patients with MBC (23). Remarkably, compared with standard imaging assessment, the determination of CTCs at baseline and follow-up appeared to have superior prognostic implications in patients with measurable MBC, particularly those with more refractory disease. Recently, De Giorgi et al. completed a retrospective analysis of 115 MBC patients who started a new line of therapy and who had CTC counts and ${ }^{18} \mathrm{~F}$-FDG PET performed at baseline and after 9-12 wk of therapy (mid-therapy) (Fig. 2) (24). In 102 evaluable patients, the median overall survival time was 14 mo (range, 1 to $>41 \mathrm{mo}$ ). Mid-therapy CTC levels correlated with ${ }^{18} \mathrm{~F}$-FDG PET/CT response in 68 evaluable patients $(67 \%)$. In univariate analysis, mid-therapy CTC counts and ${ }^{18} \mathrm{~F}$-FDG $\mathrm{PET} / \mathrm{CT}$ response predicted overall survival $\left(P<0.001\right.$ and $P=0.001$, respectively). ${ }^{18} \mathrm{~F}-$ FDG PET/CT predicted overall survival $(P=0.0086)$ in $31(91 \%)$ of 34 discordant patients who had fewer than 5 CTCs at mid-therapy. Only mid-therapy CTC levels remained significant in a multivariate analysis $(P=0.004)$, further
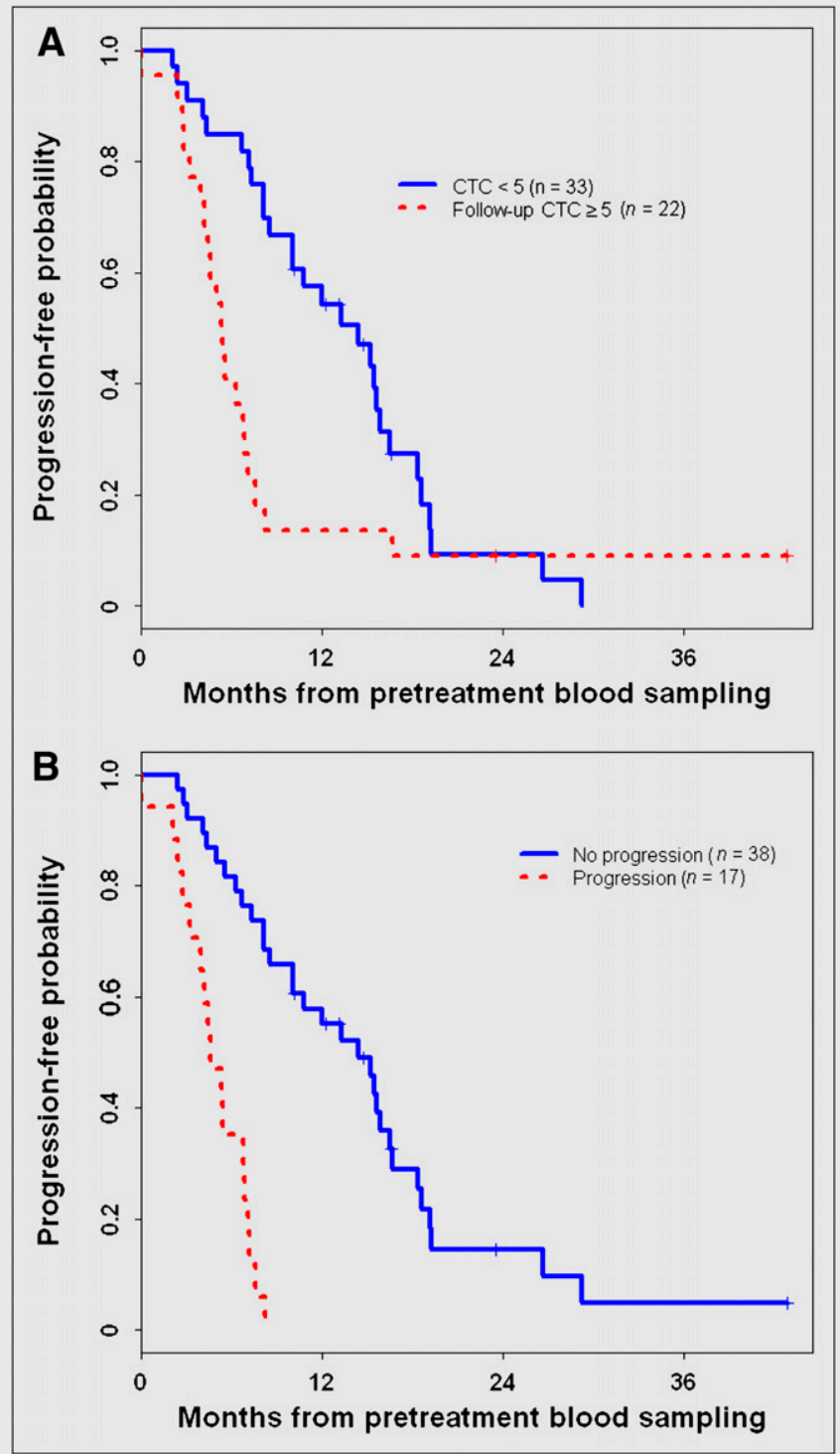

FIGURE 2. Kaplan-Meier estimates of progression-free survival by follow-up CTC count (A) and ${ }^{18} \mathrm{~F}$-FDG PET/CT response (B). (A) For patients with follow-up CTC count less than 5, survival rate was $100 \%$ at $0 \mathrm{mo}, 54 \%$ at $12 \mathrm{mo}$, and $14 \%$ at $24 \mathrm{mo}$. For patients with follow-up CTC count greater than 5 , survival rate was $100 \%$ at $0 \mathrm{mo}, 14 \%$ at $12 \mathrm{mo}, 8 \%$ at $24 \mathrm{mo}$, and $8 \%$ at 36 mo. (B) For ${ }^{18} \mathrm{~F}-\mathrm{FDG}$ PET/CT nonprogression patients, survival rate was $100 \%$ at $0 \mathrm{mo}, 55 \%$ at $12 \mathrm{mo}, 17 \%$ at $24 \mathrm{mo}$, and $6 \%$ at 36 mo. For ${ }^{18} \mathrm{~F}-\mathrm{FDG} \mathrm{PET} / \mathrm{CT}$ progression patients, survival rate was $100 \%$ at 0 mo and $35 \%$ at 6 mo. (Reprinted from (26).) 
supporting the critical importance of this test in the management of MBC.

The correlation between these different monitoring modalities in advanced disease was further refined in a subsequent analysis from the same team of investigators with particular regard to patients with bone metastases $(25,26)$. The largest study evaluated 195 patients with relapsed or progressive MBC who underwent ${ }^{18} \mathrm{~F}$-FDG PET/CT and provided blood samples for CTC analysis. Of these patients, 117 (60\%) had received prior treatment of MBC (hormonal therapy [53 patients], chemotherapy with or without hormonal therapy [48 patients], or HER2-targeted therapies combined with chemotherapy or hormonal therapy [16 patients]), whereas 78 (40\%) had new diagnoses of MBC. Interestingly, the analysis demonstrated that among the 137 patients with bone metastases at relapse or progression, $83(61 \%)$ had 5 or more CTCs, whereas $54(39 \%)$ had fewer than 5 CTCs $(P=$ 0.0122). Higher CTC numbers were detected in patients with bone metastases alone and in patients with bone metastases plus other sites of metastasis than in patients without bone metastases. Moreover, higher CTC numbers were detected in patients with more extensive bone metastases than in patients with only 1 or 2 bone lesions. With regard to the correlation with imaging findings, all but 7 of the 137 patients with bone metastases had increased ${ }^{18} \mathrm{~F}$-FDG uptake within 1 or more lesions. Of those 7, 4 had fewer than 5 CTCs, and 2 of the remaining 3 (with 5 or more CTCs) also had liver metastases with elevated ${ }^{18} \mathrm{~F}$-FDG uptake (143 and $25 \mathrm{CTCs}$ ), whereas 1 had a primary tumor with elevated ${ }^{18} \mathrm{~F}-\mathrm{FDG}$ uptake (75 CTCs). This represented the first demonstration of a significant association between CTC detection and bone metastases and supported the use of PET/CT for the evaluation of patients with this predominance in this disease site. Moreover, the increasing numbers of molecularly targeted therapies in advanced breast cancer suggest the need to introduce sensitive imaging (PET/CT) and diagnostic modalities to more appropriately monitor treatment benefit. For example, novel therapeutics may produce apoptosis and cell death in a subset of cancer cells without modifying the overall size of the metastatic lesion (RECIST criteria) but may produce changes in the metabolic profile of the lesion, and potentially in the CTC numbers, with obvious implications toward disease control.

In summary, CTC enumeration at baseline and follow-up demonstrated a strong association with prognosis and proved useful in therapeutic monitoring, suggesting a complementary role with current standard imaging modalities. Prospective trials are evaluating the benefit of modifying therapy on the basis of persistence of CTCs to further support the clinical utility of this testing in MBC. Moreover, biologic characterization of CTCs can support real-time monitoring of molecularly targeted therapies in conjunction with standard or functional imaging modalities, including PET/CT.

\section{ACKNOWLEDGMENT}

No potential conflict of interest relevant to this article was reported.

\section{REFERENCES}

1. Gambhir SS. Just what is molecular imaging? MI Gateway. SNM Web site. Available at: http://interactive.snm.org/docs/MICOE\%20Newsletter_2007-1-web. pdf. Accessed August 31, 2011.

2. Bach PB. Limits on Medicare's ability to control rising spending on cancer drugs. N Engl J Med. 2009;360:626-633.

3. Barwick T, Bencherif B, Mountz JM, Avril N. Molecular PET and PET/CT imaging of tumour cell proliferation using F-18 fluoro-L-thymidine: a comprehensive evaluation. Nucl Med Commun. 2009;30:908-917.

4. Apisarnthanarax S, Alauddin MM, Mourtada F, et al. Early detection of chemoradioresponse in esophageal carcinoma by $3^{\prime}$-deoxy $-3^{\prime}-{ }^{3} \mathrm{H}$-fluorothymidine using preclinical tumor models. Clin Cancer Res. 2006;12:4590-4597.

5. Chao KS. $3^{\prime}$-deoxy- $3^{\prime}-{ }^{18} \mathrm{~F}$-fluorothymidine (FLT) positron emission tomography for early prediction of response to chemoradiotherapy: a clinical application model of esophageal cancer. Semin Oncol. 2007;34(suppl 1)S31-S36.

6. Graf N, Herrmann K, den Hollander J, et al. Imaging proliferation to monitor early response of lymphoma to cytotoxic treatment. Mol Imaging Biol. 2008;10:349-355.

7. Dubois L, Landuyt W, Cloetens L, et al. $\left[{ }^{18} \mathrm{~F}\right] \mathrm{EF} 3$ is not superior to $\left[{ }^{18} \mathrm{~F}\right] \mathrm{FMISO}$ for PET-based hypoxia evaluation as measured in a rat rhabdomyosarcoma tumour model. Eur J Nucl Med Mol Imaging. 2009;36:209-218.

8. Gagel B, Reinartz $\mathrm{P}$, Demirel $\mathrm{C}$, et al. $\left[{ }^{18} \mathrm{~F}\right]$ fluoromisonidazole and $\left[{ }^{18} \mathrm{~F}\right]$ fluorodeoxyglucose positron emission tomography in response evaluation after chemo-/ radiotherapy of non-small-cell lung cancer: a feasibility study. BMC Cancer. 2006;6:51.

9. Lee N, Nehmeh S, Schoder H, et al. Prospective trial incorporating pre-/midtreatment $\left[{ }^{18} \mathrm{~F}\right]$-misonidazole positron emission tomography for head-and-neck cancer patients undergoing concurrent chemoradiotherapy. Int J Radiat Oncol Biol Phys. 2009; 75:101-108.

10. Doss M, Zhang JJ, Belanger MJ, et al. Biodistribution and radiation dosimetry of the hypoxia marker ${ }^{18} \mathrm{~F}-\mathrm{HX} 4$ in monkeys and humans determined by using whole-body PET/CT. Nucl Med Commun. 2010;31:1016-1024.

11. van Loon J, Janssen MH, Ollers M, et al. PET imaging of hypoxia using $\left[{ }^{18} \mathrm{~F}\right]$ HX4: a phase I trial. Eur J Nucl Med Mol Imaging. 2010;37:1663-1668.

12. Murakami Y, Takamatsu H, Taki J, et al. ${ }^{18} \mathrm{~F}$-labelled annexin V: a PET tracer for apoptosis imaging. Eur J Nucl Med Mol Imaging. 2004;31:469-474.

13. Cauchon N, Langlois R, Rousseau JA, et al. PET imaging of apoptosis with ${ }^{64} \mathrm{Cu}-$ labeled streptavidin following pretargeting of phosphatidylserine with biotinylated annexin-V. Eur J Nucl Med Mol Imaging. 2007;34:247-258.

14. Jemal A, Siegel R, Xu J, Ward E. Cancer statistics, 2010. CA Cancer J Clin. 2010;60:277-300.

15. Pagani O, Senkus E, Wood W, et al. International guidelines for management of metastatic breast cancer: can metastatic breast cancer be cured? J Natl Cancer Inst. 2010;102:456-463.

16. Cristofanilli M, Budd GT, Ellis MJ, et al. Circulating tumor cells, disease progression, and survival in metastatic breast cancer. N Engl J Med. 2004;351:781-791.

17. Cohen SJ, Punt CJ, Iannotti N, et al. Relationship of circulating tumor cells to tumor response, progression-free survival, and overall survival in patients with metastatic colorectal cancer. J Clin Oncol. 2008;2008:3213-3221.

18. de Bono JS, Scher HI, Montgomery RB, et al. Circulating tumor cells predict survival benefit from treatment in metastatic castration-resistant prostate cancer. Clin Cancer Res. 2008;14:6302-6309.

19. Mego M, Mani S, Cristofanilli M. Molecular mechanisms of metastasis in breast cancer: clinical applications. Nature Rev Clin Oncol. 2010;7:693-701.

20. Reuben JM, Lee BN, Li C, et al. Circulating tumor cells and biomarkers: implications for personalized targeted treatments for metastatic breast cancer. Breast J. 2010;16:327-330.

21. Aktas B, Tewes M, Fehm T, et al. Stem cell and epithelial-mesenchymal transition markers are frequently overexpressed in circulating tumor cells of metastatic breast cancer patients. Breast Cancer Res. 2009;11:R46.

22. Dawood S, Broglio K, Valero V, et al. Circulating tumor cells in metastatic breast cancer: from prognostic stratification to modification of the staging system? Cancer. 2008;113:2422-2430.

23. Budd GT, Cristofanilli M, Ellis MJ, et al. Circulating tumor cells versus imaging: predicting overall survival in metastatic breast cancer. Clin Cancer Res. 2006;12:6403-6409.

24. De Giorgi U, Valero V, Rohren $\mathrm{E}$, et al. Circulating tumor cells and $\left[{ }^{18} \mathrm{~F}\right]$ fluorodeoxyglucose positron emission tomography/computed tomography for outcome prediction in metastatic breast cancer. J Clin Oncol 2009;27:3303-3311.

25. De Giorgi U, Valero V, Rohren E, et al. Circulating tumor cells and bone metastases as detected by FDG-PET/CT in patients with metastatic breast cancer. Ann Oncol. 2010;21:33-39.

26. De Giorgi U, Mego M, Rohren EM, et al. ${ }^{18} \mathrm{~F}-\mathrm{FDG}-\mathrm{PET} / \mathrm{CT}$ findings and circulating tumor cell counts in the monitoring of systemic therapies for bone metastases from breast cancer. J Nucl Med 2010;51:1213-1218. 